Research Paper:

\title{
Effects of Professional Labor Support Education to Iranian Midwifery Students on Mothers' Satisfaction
}

\author{
Seyedeh Fatemeh Vasegh Rahimparvar ${ }^{1,2}$ (D), Golnar Nasehi ${ }^{1,2,3^{*}}$ (D), Zohreh Khakbazan ${ }^{1,2}$ (D), Anooshirvan Kazemnejad ${ }^{4}$ \\ 1. Department of Reproductive Health, School of Nursing and Midwifery, Tehran University of Medical Sciences, Tehran, Iran \\ 2. Department of Midwifery, School of Nursing and Midwifery, Tehran University of Medical Sciences, Tehran, Iran. \\ 3. Department of Midwifery and Reproductive Health, School of Nursing and Midwifery, Iran University of Medical Sciences, Tehran, Iran. \\ 4. Department of Biostatistics, Faculty of Medical Sciences, Tarbiat Modares University, Tehran, Iran.
}

\begin{tabular}{|c|c|}
\hline $\begin{array}{l}\text { Use your device toscan } \\
\text { and read the article online }\end{array}$ & cittation Vasegh Rahimparvar, S. F., et al., 2018. Effects of Professional Labor Support Education to Iranian Midwifery Students \\
\hline 口舟步回 & on Mothers' Satisfaction. Journal of Client-Centered Nursing Care, 4(3), pp. 123-130. https://doi.org/10.32598/jccnc.4.3.123 \\
\hline 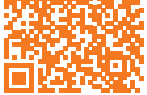 & doij https://doi.org/10.32598/jecnc.4.3.123 \\
\hline
\end{tabular}

(c) (i) (s)

Article info:

Received: 03 Jan 2018

First Revision: 05 Feb 2018

Accepted: 25 Jun 2018

Published: 01 Aug 2018

Keywords:

Labor support, Midwifery student, Education,

Satisfaction, Iran

\section{A B S T RA C T}

Background: Majority of the textbooks for undergraduate midwifery students of Iran are educational resources for obstetricians. Therefore, the topic of Professional Labor Support is not taught well to these students. This study aimed to determine the effect of Professional Labor Support education to midwifery students (based on midwifery textbooks) on satisfaction of women who gave birth under the supervision of these students.

Methods: This quasi-experimental study was conducted on 70 midwifery students of a nursing and midwifery school in Iran. Students in the intervention group $(n=35)$ were taught Professional Labor Support in physical, emotional, and informational fields based on midwifery textbooks. The control group received conventional education. The effect of Professional Labor Support education on the students was evaluated using Professional Labor Support Questionnaire (LSQ) and satisfaction of women who gave birth under the supervision of these students (measured by a modified version of LSQ). Data analysis was conducted by Chi-square, two-sample Kolmogorov-Smirnov and Independent $t$ tests in SPSS V. 16.

Results: The Professional Labor Support delivered by the midwifery students in the intervention group was significantly higher than the control group $(\mathrm{t}=-9.16, \mathrm{P}<0.001)$. Similarly, the satisfaction of women who had given birth under supervision of the trained students was significantly higher than that of women who had given birth under the supervision of the control group $(\mathrm{P}<0.001)$.

Conclusion: Professional Labor Support education based on midwifery textbooks had a positive effect on the women's satisfaction with labor support. It is suggested that textbooks for obstetricians be replaced by midwifery textbooks recommended by International Confederation of Midwives.

\footnotetext{
* Corresponding Author:

Golnar Nasehi, PhD.

Address: Department of Reproductive Health, School of Nursing and Midwifery, Tehran University of Medical Sciences, Tehran, Iran.

Tel: +98 (938) 3875152

E-mail: golnar_nms@yahoo.com
} 


\section{Highlights}

- Midwifery textbooks are more appropriate than obstetrical textbooks for teaching professional labor support to midwifery students.

- Midwifery students who studied labor support based on these textbooks satisfied women, who had given birth under their care.

\section{Plain Language Summary}

Labor support is an important factor for the satisfaction of women during childbirth. Currently, labor support is taught based on Obstetrical textbooks. However, Midwifery textbooks are a better source for teaching this topic to Iranian midwifery students. Our research showed that the women who had given birth under the supervision of educated students with Midwifery textbooks were more satisfied.

\section{Background}

rofessional Labor Support is an important objective for midwifery care. The term "Professional Labor Support" refers to constant non-pharmacological care provided to women during labor. Professional Labor Support includes physical, emotional, and informational supports as well as maintaining the mother's privacy (Teshome, Abdella $\&$ Kumbi 2007). Therefore, to meet the emotional and support needs of women, including pain management and coping with childbirth stress, each woman should be constantly under the care and support of a midwife (Farahani et al. 2005). Interventional studies in Iran have shown the positive effect of midwifery support during labor on women's satisfaction (Mirmolaei et al. 2007; Mortazavi et al. 2012).

A cross-sectional study from midwives' perspective in Iran concluded that the application of Professional Labor Support by the midwives was insufficient and one of its most important pitfalls was lack of skill and experience. Furthermore, there is a need to eliminate this barrier and valorize the given support (Vasegh RahimParvar et al. 2012a). Accordingly, teaching the midwifery students is very important for empowerment of the parturient to cope with labor (Vasegh Rahimparvar et al. 2013).

Childbirth because of its profound physical, mental and emotional effects is an important physiological event in a woman's life (Sasito et al. 2001). The rate of cesarean section in Iran is 3-4 times higher than the accepted rate of the World Health Organization (Ahmad-Nia et al. 2009). Several studies in Iran have reported that fear of childbirth is the most important factor for requesting ce- sarean section delivery (Fahami, Masoudfar \& Davazdahemami 2008; Negahban \& Ansari 2009). Because of the inadequate Professional Labor Support, many Iranian pregnant women become anxious leading to experience an abnormal progression of labor and finally a caesarean section (Vasegh Rahimparvar et al. 2012b).

Quality of midwifery care is one of the issues that has considerable effects on childbirth outcomes. Performance and actions of midwife in this critical situation can result in different outcomes that not only determine life, death, health, or physical injuries, but also have a significant impact on the mental and emotional health of mother and baby (Fraser \& Cooper 2009; Page 2000; Ranjbar, Behboodi Moghadam \& Gharacheh 2017). What a woman remembers from giving birth is one of the most important consequences of childbirth (Page 2000). Therefore, improvement of the quality of care without considering the opinions and expectations of the patients is not possible. Midwives are key members of primary health care team and play an important role in providing care before and after the childbirth. Consequently, they should be aware of the factors influencing patient's satisfaction (Mirmolaei et al. 2007).

With regard to midwifery education and given the wide responsibilities of a midwife in prenatal and childbirth care, the question arises as to whether midwives in Iran acquire this vast range of skills in their education. It seems that midwifery students in Iran do not properly receive such specialized education on methods of labor pain relief and preparation for delivery (Tork Zahrani 2008; Ministry of Health 2010). Ahmady and Yazdi (2016) in a qualitative study in Iran entitled "Exploring the midwifery training challenges in Iran from the viewpoint of faculty members and graduates of this field" 
reported that all participants considered "weakness of educational program" as one of the main obstacles of the anarchy of midwifery education and one of its main sub-themes was "lack of educational resources". Educational resources are of particular importance. Rich resources play a distinctive role for teachers and students' learning. Appropriate educational resources are important pillars of education.

The current curriculum of midwifery in Iran uses Williams Obstetrics book (which is written for obstetricians not for midwives) as the main textbook of pregnancy and childbirth course for midwifery students (Vasegh Rahimparvar et al. 2013). International Confederation of Midwives (ICM) (2012) has recommended several resources for midwifery education and there are also textbooks and other valuable resources for midwives in the world. However, the participants of a qualitative study in Iran believed that there were no textbooks in the world providing the necessary theoretical and scientific issues to prepare midwifery students to respond to community health needs (Ahmady \& Yazdi 2016). In addition, some of the midwifery authorities in education believe that the midwifery textbooks are not enough for midwifery students and they should study the obstetrician's textbooks as the main resource (Hashemi \& Vasegh Rahimparvar 2016).

Since midwives play a crucial role in delivery, they should have adequate knowledge to provide support during labor. It is essential to improve the knowledge, attitude, and professional competence of midwives in the field of Professional Labor Support. Although, Professional Labor Support does not require special equipment, it should be delivered by educated individuals in midwifery schools of the country. In Iran, theoretical and practical courses have been designed for educating midwifery students; however, Professional Labor Support has not been regarded as a special course credit in midwifery educational program (Vasegh Rahimparvar et al. 2013).

Professional Labor Support discussions have not been properly incorporated into the midwifery curriculum and the main textbooks of midwifery students are textbooks of obstetricians in Iran. Accordingly, this study was designed to examine the effect of Professional Labor Support education to Iranian midwifery students (based on midwifery textbooks), on mothers' satisfaction with labor support. The results may emphasize Professional Labor Support education based on midwifery resources to midwifery students in Iran.

\section{Materials and Methods}

\section{Design and sample}

This was a quasi-experimental study which examined the effect of Professional Labor Support education to Iranian midwifery students on the satisfaction of women who gave birth under their supervision. The students $(n=70)$ were recruited by census in 2011. They were midwifery students of Nasibeh Nursing and Midwifery School of Sari City, Iran. The students were selected from all eighth, sixth, or fifth semester, studying in the fourth or third year of education. Then, they were divided into two groups using quota sampling. Equal number of students in each level were placed in each group. The students had passed practical course in 3 educational hospitals affiliated to Mazandaran University of Medical Sciences (Imam Ali Hospital in Amol, Shohada Hospital in Behshahr, and Imam Hospital in Sari City).

Inclusion criteria were having passed all the theoretical pregnancy and delivery courses and passing their practical course of delivery in one of these hospitals. Exclusion criteria were absence of intervention group students from theoretical course or more than one day absence in practical course. Characteristics of the pregnant women included having term and single fetus with cephalic presentation, lacking internal or surgical problems, delivering normally a healthy baby, and lacking any complications after delivery.

\section{Data instruments}

Data collection tool was a questionnaire consisting of three sections: demographic characteristics, Labor Support Questionnaire (LSQ), which as a paper-pencil test was completed by the students, and a researcher-made questionnaire for measuring women's satisfaction with received labor support designed based on LSQ and completed by the mothers. LSQ has 27 items and scored based on a 6-point Likert-type scale with a range of responses from 0 to 5 based on the amount of the received support. In general, this questionnaire has a maximum score of 135 . Scores between 0 and 44 indicate weak support, between 45 and 89 represents average support, and between 90 and 135 indicates strong support.

LSQ has four subitems, including physical (6 items with maximum score of 30), emotional (13 items with maximum score of 65), and informational (3 items with maximum score of 15) as well as supporting the mother's decisions ( 5 items with maximum score of 25). There is also a single question in the end of LSQ: "Were there any 
problems with using professional support during labor?" The Cronbach alpha for LSQ is 0.90 (Salus 2006). LSQ has been translated into Persian with suitable validity and reliability. To assess the validity of the questionnaire for women's satisfaction, content validity was used. In addition, to confirm the reliability of the questionnaire, test-retest with correlation coefficient of 0.80 was used (Vasegh Rahimparvar et al. 2013).

Demographic characteristics form and LSQ were completed by all students before the intervention. The mothers who had given birth under supervision of these students also completed the researcher-made questionnaire after delivery. The difference of this questionnaire with LSQ was that, instead of asking if they did certain things during labor, they were asked if certain things were done for them during labor. The scoring was similar to main LSQ; however, 6 questions were removed from it. The special questionnaire for mothers consisted of $21 \mathrm{yes} /$ no questions about provision of Professional Labor Support by midwifery students.

Mothers in the control and intervention groups who answered 'yes' could answer the question in the next column which measured the satisfaction based on a 5-point Likert-type scale ranging from "Not at all", to "Very high". Based on the positive or negative direction, scores of 1-6 were assigned for each question, that is, the lowest amount of the satisfaction (Not at all) was scored 1 and the highest amount of the satisfaction (Very high) scored 6 . After calculating the scores, the mothers were divided into three groups of low satisfaction (0-41), average satisfaction (42-83), and high satisfaction (84-126).

\section{Study procedure}

The students in the control group were selected prior to intervention, and during the first two months of the semester in order to minimize the possibility of information exchange between the groups. The designed program was implemented during the next 2 months of the semester for the intervention group. To develop this program, first the researchers prepared the initial content using midwifery textbooks recommended by ICM and relevant articles using effective teaching methodologies (International Confederation of Midwive 2012). A 1-day, 5-hour training course was held for the intervention group in the form of lecture and question and answer session along with displaying a video and slides emphasizing on the midwifery students' capabilities in the Professional Labor Support. The content of the education course included the importance of Professional Labor Support, encouraging the mother to walk and change her position, constant presence of midwife beside the mother and meeting her physical needs, as well as massaging her back, belly, and legs.

The discussion about emotional and spiritual supports included encouraging the mother to cooperate during labor, maintaining eye contact with the mother and talking gently with her with the aim of distraction, breathing techniques along with calming the mother, and standing next to the mother to meet her demands. The discussion was also about methods of giving information to the mother about labor progression and talking to her when she loses her self-confidence. In addition, the discussion was about establishing security and supporting the mother's decisions during labor by eliminating environmental stressors and, if necessary, eliminating despicable environmental factors, establishing a sense of security by regular control of the mother and giving clear answers to her questions. Thus conforming to the definition of Professional Labor Support, the intervention group got familiarized with different types of these supports.

The control group consisted of students who had received only routine education based on the obstetricians' textbooks. The intervention group received both routine and interventional education. The LSQ was completed by all students before and after supervision of three deliveries. The women under supervision of these students also completed the questionnaire an hour after delivery.

\section{Data analysis}

SPSS version 16 was used for data analysis. The students and mothers' age did not have normal distribution; therefore, two-sample Kolmogorov-Smirnov test was used for comparing the groups. Comparison between categorical demographic variables and the women's satisfaction was done by the Chi-square test. Independent $t$ test was used for comparing LSQ scores between two groups before intervention, and after the intervention. LSQ score difference before and after the intervention was compared between two groups by Independent $\mathrm{t}$ test. The $\mathrm{P}$ value was considered significance at less than 0.05 .

\section{Results}

Three midwifery students in the intervention group were excluded due to absence from the education course. Therefore, 32 students participated in the intervention group and 35 in the control group. 


\section{Study subjects demographics}

Mean \pm SD ages of the students were $21.66 \pm 0.6$ and $21.74 \pm 0.92$ years, and the mothers' mean age were $26 \pm 4.7$ and $24.11 \pm 3.81$ years in the intervention and control group, respectively. The Mean \pm SD number of deliveries in the intervention and control group were $0.88 \pm 0.61$ and $0.94 \pm 0.64$, respectively. Majority of the mothers were housewife and had diploma or higher education. Two midwifery students groups and women who gave birth under the supervision of these students were homogeneous in terms of all demographic characteristics.

\section{Labor Support Questionnaire}

Mean \pm SD of LSQ score prior to intervention was $82.63 \pm 10.14$ in the control group and $84.70 \pm 44.9$ in the intervention group; and the two groups were similar in this regard. Furthermore Mean \pm SD of LSQ score after intervention was $54.59 \pm 40.19$ in the control group and $78.90 \pm 74.18$ in the intervention group which was a significant statistical difference between the two groups $(\mathrm{P}<0.001)$. Table 1 indicates that mean LSQ score difference before and after the intervention between the groups was significant in all fields $(\mathrm{t}=-9.16, \mathrm{P}<0.001)$, except in supporting mother's decisions field $(\mathrm{t}=-1.90$, $\mathrm{P}=0.610$ ). Moreover, the education increased the use of
Professional Labor Support (in the physical, emotional, and informational fields) by midwifery students.

Regarding responses to the question "Were there any problems in using professional support during labor?" there was a significant difference between the intervention and control group $(\mathrm{P}=0.047)$. Majority of the students in the control group (compared to the intervention group) reported their problems in implementing Professional Labor Support. In addition, with regard to problems in providing support care, there was a significant difference between the intervention and control group in a way that, students in the control group considered lack of skill and experience as a problem in providing professional support during labor more than students in the intervention group $(\mathrm{P}=0.003)$. This indicates that students' education has had a positive effect in reducing the problems in using Professional Labor Support in the intervention group.

Regarding the question about the problems in providing support care, students mentioned problems such as lack of facilities (e.g. bathtub or Jacuzzi), absence of relatives, especially the husband, and multi-bed rooms which make it impossible to support the mother's decisions in implementing Professional Labor Support.

Table 1. Mean \pm SD of labor support score difference of the control and intervention groups of midwifery students before and after the intervention

\begin{tabular}{cccc}
\hline Field & Control & Intervention & Significance Level \\
\hline Physical & $2.76 \pm-1.51$ & $6.03 \pm 4.08$ & $\mathrm{t}=-8.93, \mathrm{P}<0.001$ \\
Support mother's decisions & $2.08 \pm 1.48$ & $3.14 \pm 2.66$ & $\mathrm{t}=-1.90, \mathrm{P}=0.610$ \\
Emotional & $-6.23 \pm 4.90$ & $6.40 \pm 3.84$ & $\mathrm{t}=-7.72, \mathrm{P}<0.001$ \\
Informational & $1.24 \pm-0.60$ & $3.84 \pm 2.64$ & $\mathrm{t}=8.93, \mathrm{P}<0.001$ \\
All fields & $9.06 \pm-4.28$ & $19.94 \pm 12.4$ & $\mathrm{t}=-9.16, \mathrm{P}<0.001$ \\
\hline
\end{tabular}

Table 2. Frequency of mothers' satisfaction with received labor support in the intervention and control groups

\begin{tabular}{cccc}
\hline & \multicolumn{2}{c}{ No. (\%) } & Significance Level \\
\cline { 2 - 3 } Satisfaction & Intervention & Control & \\
\hline Low & $0(0)$ & $6(17.1)$ & $P<0.001$ \\
Moderate & $4(12.5)$ & $26(74.3)$ & \\
High & $28(87.5)$ & $3(8.6)$ & \\
\hline
\end{tabular}


Regarding the women's satisfaction with received labor support, the results present (Table 2) a significant difference between the intervention and control group $(\mathrm{P}<0.001)$. Mothers delivered under the supervision of educated students had received more Professional Labor Support than those delivered under the supervision of the students in the control group. This finding indicates that educating the students had a positive effect on the satisfaction of women in the intervention group. Women in the intervention group were more satisfied with their delivery than women in the control group $(\mathrm{P}<0.001)$. Considering their experience in this delivery, they were ready to receive the same support for their next delivery and suggested that other women receive the same support as they received for their current delivery.

\section{Discussion}

In Iran, the main recommended textbooks for teaching in midwifery schools are obstetricians' textbooks (Vasegh Rahimparvar et al. 2013). Some studies have shown that Iranian midwives do not have satisfactory performance in Professional Labor Support practice (Vasegh Rahimparvar et al. 2012a; Vasegh Rahimparvar et al. 2013). Using midwifery textbooks in midwifery schools is an important challenge for midwifery educational planners (Ahmady \& Yazdi 2016). This study aimed to determine the effect of Professional Labor Support education to midwifery students (based on midwifery textbooks) on the satisfaction of women who gave birth under the supervision of these students.

The study results indicated that teaching according to midwifery textbooks, as an intervention, had a positive effect on using labor support behaviors by midwifery students. In line with this finding, some related studies have shown significant improvement of midwives' performance in labor pain relief methods as one of the most important support behaviors (Akhoondzadeh et al. 2005). In addition, several other midwifery studies indicate the positive effect of education on increasing the use of desirable methods (Haghighi, Ebrahimi \& Zadeh 2007; Kimber et al. 2008).

In this study, lack of skill and experience was a key factor in midwifery students' failure to use support behaviors; a study conducted by Vasegh Rahimparvar et al. (2012a) in Tehran, confirmed this finding. This study showed that using support behaviors by educated midwifery students had a positive effect on mothers' satisfaction that received labor support. In the study in the United States, Tumblin and Simkin (2001) reported that women expect a high degree of physical, emotional, and informational support. Support during labor improves the outcome of labor, in a way that when highly skilled individuals help women to cope with labor stress, women's satisfaction with their delivery experience increases.

Several studies in Iran have reported similar results and are consistent with this study result, which indicates the positive effect of using Professional Labor Support on mothers' satisfaction (Mirmolaei et al. 2007; Keshavarz, Shariati \& Jahdi 2008). The difference between this study and the reported studies is the method of intervention. In this study, the Professional Labor Support was taught to midwifery students and then its effects on the mother's satisfaction were investigated. But the reported research studies directly investigated the effects of Professional Labor Support on the mother's satisfaction.

In Iran, the main textbooks of midwifery students are the obstetricians' textbooks. Consequently the findings could help to make changes in midwifery education of Iran and other countries with similar curriculum. In this study, Professional Labor Support education to midwifery students based on special midwifery textbooks had positive effects on increasing the Professional Labor Support by the students, and the satisfaction of the women who gave birth under the supervision of these students.

It is recommended that more specialized course credits such as Professional Labor Support and its different areas be incorporated into the curriculum of Iranian midwifery students. It seems that midwifery textbooks play a major role in creating professional attitude and teaching special responsibilities of this field. Currently, the main reference textbook of the course on pregnancy and childbirth for midwifery students is Williams Obstetrics, which seems to be a more appropriate textbook for obstetricians. This book primarily focuses on the topics related to obstetricians and has little information on the Professional Labor Support. Therefore, more emphasis on teaching Professional Labor Support to midwifery students is recommended. Accordingly, like other countries, the main reference textbooks of midwifery students should be selected from special textbooks for these students.

Doing similar studies in other midwifery educational environments is recommended in Iran, through random sampling method. In addition, further research is recommended on strategies for using this program, and attitude of midwifery teachers and students about midwifery textbooks. 


\section{Ethical Considerations}

\section{Compliance with ethical guidelines}

This study was approved by the Ethics Committee of Tehran University of Medical Sciences. Informed consent was obtained from the participated students and mothers. The clinical trial registration code was $201103025918 \mathrm{~N} 2$.

\section{Funding}

The present paper was extracted from the MSc. thesis of the second author, in Research Deputy of Tehran University of Medical Sciences with the contract No. D/250/3267.

\section{Authors contributions}

Conceptualization: Seyedeh Fatemeh Vasegh Rahimparvar; Methodology: Seyedeh Fatemeh Vasegh Rahimparvar, Golnar Nasehi, Zohreh Khakbazan; Data collection: Golnar Nasehi; Analysis: Anooshirvan Kazemnejad; Writing-original draft: Seyedeh Fatemeh Vasegh Rahimparvar and Golnar Nasehi; Review and Editing: All authors; and Supervision: Seyedeh Fatemeh Vasegh Rahimparvar.

\section{Conflicts of interest}

The authors declared no conflict of interest.

\section{Acknowledgements}

We appreciate the sincere assistance of the managers and faculty members of the School of Nursing and Midwifery, Tehran University of Medical Sciences, Nasibeh Nursing and Midwifery School in Sari, administration of Imam Ali Hospital in Amol, Imam Hospital in Sari, and Shohada Hospital in Behshahr.

\section{References}

Ahmad Nia, S., et al., 2009. Caesarean section in the Islamic Republic of Iran: Prevalence and some sociodemographic correlates. Eastern Mediterranean Health Journal, 15(6), pp. 1389-98. [PMID]

Ahmady, S. \& Yazdi, L., 2016. Exploring the midwifery training challenges in Iran from the viewpoint of faculty members and graduates of this field: Content analysis. Journal of Medical Education, 15(2), pp. 82-89.

Akhoondzadeh, A., et al., 2005. [Survey of effect of education of labore pain relief on knowledge, attitude and practice of midwives
(Persian)] [PhD. dissertation]. Tehran: Tehran University of Medical Sciences.

Haghighi, N. B., Ebrahimi, H. \& Zadeh, M. D., 2007. [Effects of education on midwifery students' knowledge and skill in neonatal resuscitation (Persian)]. Strides in Development of Medical Education, 4(2), pp. 116-24.

Fahami, F., Masoudfar, S. \& Davazdahemami, S., 2008. The ef fect of lamaze practices on the outcome of pregnancyand labor in primpara women. Iranian Journal of Nursing and Midwifery Research, 12(3), pp. 111-4.

Fraser, D. M., Cooper, M. A., 2009. Myles textbook for midwives Philadelphia: Churchill Livingstone.

Hashemi, M., 2016. [Factors associated with training Professional Labor Support to midwifery students in Tehran (Persian)] [MSc. thesis]. Tehran: Tehran University of Medical Sciences.

International Confederation of Midwives (ICM)., 2012. International Confederation of Midwives' Model Curriculum Outlines for Professional Midwifery Education. Hague: International Confederation of Midwives.

Keshavarz, M., Shariati, M. \& Jahdi, F., 2008. Effects of complementary therapies on pain and labor outcomes in nuliparous women referred to delivery unit in Fatemiyeh Hospital in Shahrood City (2003-2005). Medical Science Journal of Islamic Azad Univesity-Tehran Medical Branch, 18(4), pp. 245-50.

Kimber, L., et al., 2008. Massage or music for pain relief in labour A pilot randomised placebo controlled trial. European Journal of Pain, 12(8), pp. 961-9. [DOI:10.1016/j.ejpain.2008.01.004] [PMID]

Ministry of Health, 2010. [Midwife's job description (Persian)] [Internet]. Viewed 20 Jun. 2009, http://www.behdasht.gov.ir/ news/\%D8\%B3\%D8\%A7\%DB\%8C\%D8\%B1/5878/\%D8\%B4 \%D8\%B1\%D8\%AD+\%D9\%88\%D8\%B8\%D8\%A7\%D9\%8A\% D9\%81+\%D9\%85\%D8\%A7\%D9\%85\%D8\%A7+

Mirmolaei, S. T., et al., 2007. [Prenatal care utilization rate and patients satisfaction (Persian)]. Journal of Hayat, 13(2), pp. 31-40

Mirmawlai, T., Mehran, A. \& Rahimi Gasabeh, S., 2003. [Mother's opinions concerning the importance of and their satisfaction with support received in the labor and delivery rooms (Persian)]. Journal of Hayat, 9(2), pp. 41-8.

Farahani, S. M., et al., 2005. [Effect of the one to one midwifery care during labor on modes of delivery (Persian)]. Iran Journal of Nursing, 18(43), pp. 71-82.

Mortazavi, S. H., et al., 2012. Effects of massage therapy and presence of attendant on pain, anxiety and satisfaction during labor. Archives of Gynecology and Obstetrics, 286(1), pp. 19-23. [DOI: 10.1007/s00404-012-2227-4] [PMID]

Negahban, T. \& Ansari, A., 2009. [Does fear of childbirth predict emergency cesarean section in primiparous women (Persian)]. Journal of Hayat, 14(4), pp. 73-81.

Page, L. A. \& McCandlish, R., 2006. The new midwifery E-book: Science and sensitivity in practice. London: Churchill Livingstone.

Ranjbar, F., Behboodi Moghadam, Z. \& Gharacheh, M., 2017. Prenatal care in pregnancies through Assisted Reproductive Technologies (ARTs): A narrative review article. Journal of Client-Centered Nursing Care, 3(4), pp. 241-50. [DOI:10.32598/ jccnc.3.4.241] 
Saisto, T., Kaaja, R., Ylikorkala, O. \& Halmesmäki, E., 2001. Reduced pain tolerance during and after pregnancy in women suffering from fear of labor. Pain, 93(2), pp. 123-7. [PMID]

Sauls, D.J., 2006. Dimensions of professional labor support for intrapartum practice. Journal of Nursing Scholarship, 38(1), pp. 36-41. [PMID]

Teshome, M., Abdella, A. \& Kumbi, S., 2007. Parturients' need of continuous labor support in labor wards. The Ethiopian Journal of Health Development, 21(1), pp. 35-9.

TorkZahrani, S., 2008. Commentary: Childbirth education in Iran. The Journal of Perinatal Education, 17(3), pp. 51-4. [DOI:10.1624/105812408X329601] [PMID] [PMCID]

Tumblin, A. \& Simkin, P., 2001. Pregnant women's perceptions of their nurse's role during labor and delivery. Birth, 28(1), pp. 52-6. [PMID]

Vasegh Rahimparvar, S. F., et al., 2012a. [Application of Professional Labor Support in university hospitals of Tehran City and related affecting factors (Persian)]. The Iranian Journal of Obstetrics, Gynecology and Infertility, 15(4), pp. 29-34. [DOI:10.22038/ijogi.2012.5732]

Vasegh Rahimparvar, S. F., et al., 2012b. Effect of educational software on self-efficacy of pregnant women to cope with labor: A randomized controlled trial. Archives of Gynecology and Obstetrics, 286(1), pp. 63-70. [DOI:10.1007/s00404-012-2243-4]

Vasegh Rahimparvar, S. F., et al., 2013. Design, implementation and evaluation of educational program in continuous labor support to midwifery students. The Iranian Journal of Obstetrics, Gynecology and Infertility, 16(79), pp. 10-7. 